\title{
Early Life Ecology of Skipjack Tuna, Katsuwonus pelamis, Based on Survey Cruises off Palau and Micronesia, 1992-1996
}

\author{
Toshiyuki TANABE ${ }^{*}$, Miki OGURA ${ }^{1}$ and Mio TAKAHASHI ${ }^{1}$ \\ Resources Management Division, Tohoku National Fisheries Research Institute \\ (3-27-5 Shinhama, Shiogama, Miyagi, 985-0001 Japan)
}

\begin{abstract}
In order to clarify the ecological habit of the skipjack tuna, Katsuwonus pelamis, at the juvenile stage, we implemented a research program from 1992 to 1996 . For the main activity of the program, we conducted survey cruises to determine the distribution of juvenile skipjack tuna in the offshore areas of Palau and Micronesia, in the tropical western Pacific, during October to December. We developed a new sampling gear, a high-speed midwater trawl net with a large mouth that enables to collect large numbers of juvenile tunas. We analyzed the relationship between the horizontal and vertical distribution of the juveniles and oceanographic conditions, feeding habit of the juveniles based on stomach content analysis, and growth process of juveniles by otolith increment analysis. The results of our analyses indicated that juvenile skipjack tuna was widely distributed in the offshore area from the North Equatorial Current to the North Equatorial Counter Current, around the Palau and Micronesian Islands. We concluded that these areas were important for juvenile skipjack tuna as a nursery ground.
\end{abstract}

Discipline: Fisheries

Additional key words: juvenile, distribution, feeding habit, growth

\section{Introduction}

Skipjack tuna, Katsuwonus pelamis, is known to be a highly migratory species together with yellowfin tuna, Thunnus albacares, bigeye tuna, T. obesus, and other Thunnus species. Skipjack tuna is widely distributed from temperate to tropical areas ${ }^{7}$. Adult skipjack tuna usually forms large schools in the pelagic zone of the open oceans, and migrates between the lower and higher latitudes. The spawning ground of the skipjack is distributed at the lower latitudes, from tropical through subtropical areas. At the late stage of young fish (0-1 age), skipjack begins a migration toward the higher latitudes. A large number of schools of skipjack appear in the Japanese waters from April to October. The pre-adult fish (12 age) shows an active and voracious feeding behavior that results in rapid growth.

The fishing activities of skipjack tuna have been extended to almost all the areas where skipjack is distrib- uted. The dominant fisheries equipment in the offshore areas consists of purse-seiners and larger poleand-liners. In contrast, in the onshore areas trollers and smaller pole-and-liners predominate. Annual catch of skipjack in the western Pacific amounted to approximately 830,000 metric tons in $1997^{4}$. Thus, skipjack is one of the most important stocks for the fisheries industry in many countries. The skipjack fisheries industry essentially needs to maintain optimal stock levels and sustainable yields.

However, in contrast with the increasing importance of the skipjack stock, basic information about their ecology is insufficient. Especially, the ecology of the skipjack during the juvenile and young stages, in terms of distribution, survival, and growth is largely unknown, presumably due to the lack of techniques for sampling juveniles. Basic information about the early life history of skipjack contributes not only to the accumulation of biological data but also to the analysis of the recruitment process and assessment of the recruitment level several

\footnotetext{
Present address:

${ }^{1}$ Western Pacific Tuna and Skipjack Resources Division, National Research Institute of Far Seas Fisheries

(5-7-1 Orido, Shimizu, Shizuoka, 424-8633 Japan).

*Corresponding author: fax +81-543-35-9642, e-mail katsuwo@enyo.affrc.go.jp

Received 15 November 1999, accepted 4 February 2000.
} 
years later

Since 1992, we have implemented a research program for studies on the early life ecology of the skipjack tuna. The major objective of the project was to study the early life history of the skipjack in the western Pacific. We conducted our survey cruises for analyzing the distribution of juvenile skipjack in the offshore areas of Palau and Micronesia, in the tropical western Pacific $\left(0-20^{\circ} \mathrm{N}\right.$, $130-160^{\circ} \mathrm{E}$ ) from October to December, 1992-1996. We developed a new sampling gear, a high-speed midwater trawl net with a large mouth opening that could collect large numbers of juvenile tunas ${ }^{19)}$. Analyses of the research data provided important information about the distribution, feeding habit, and growth of juvenile skipjack in the tropical western Pacific. These results may contribute to advanced studies on skipjack population. We report here an outline of the studies on the early life ecology of the skipjack tuna.

\section{Materials and methods}

\section{1) Survey design}

The objectives of the research program were as follows: first, to develop an appropriate sampling method for juvenile skipjack; second, to accumulate biological data on juvenile skipjack using the new sampling gear; third, to provide information on the early life history of the skipjack in the western Pacific by the analysis of the research data. The project focused on the distribution,

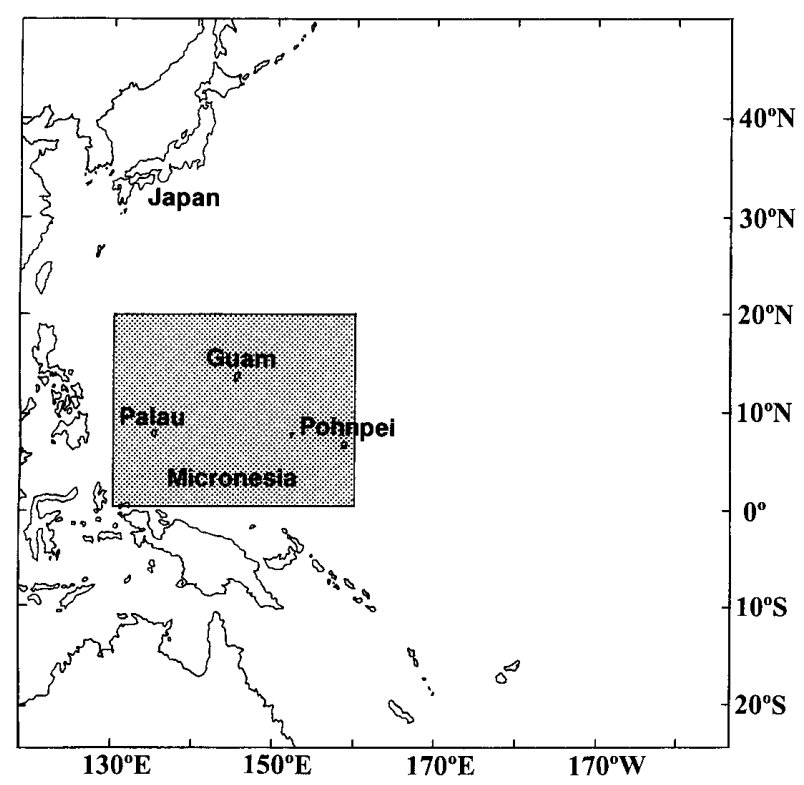

Fig. 1. The survey area

Research cruises for sampling juvenile tunas were conducted using the midwater trawl net, TANSYU, from October to December, 1992-1996. feeding habit, growth, and survival of the juvenile skipjack in the offshore area of the tropical western Pacific.

The Palau Maritime Authority (PMA), Republic of Palau, and the Micronesian Maritime Authority (MMA), Federated States of Micronesia (FSM), extended their cooperation for the selection of the survey area (Fig. 1). The area was located in the offshore waters between Palau and Caroline Islands including the exclusive economic zones of Palau and FSM. The survey was carried out during a period of 5 years from late October to early December, 1992-1996. Two research vessels were chartered for the survey cruises. Tanshu Maru, which belongs to Kasumi Senior High School in Hyogo Prefecture, was used for the 1992 and 1993 cruises. Omi Maru, which belongs to Yamaguchi Fisheries Senior High School in Yamaguchi Prefecture, was used for the 19941996 cruises. Both vessels were typical stern-trawlers of the 400-tonnage class used in Japanese fisheries high schools.

The cruise tracks with survey stations were set up before every survey cruise. The basic survey materials used in each cruise consisted of a midwater trawl net for sampling juvenile skipjack tuna, a Bongo net or a larval net with a $2 \mathrm{~m}$-diameter ring for sampling larvae, and a CTD (SEA-BIRD ELECTRONICS Inc., SBE-19) for the observation of vertical profiles of temperature and salinity.

\section{2) Development of new sampling gear}

The midwater trawl net, TANSYU, having a large mouth opening, was designed to be towed at a high speed. It was developed in cooperation with Tohoku National Fisheries Research Institute and Nichimo Co., Ltd. Targets for the TANSYU included skipjack and other tunas, from 10 to $200 \mathrm{~mm}$ in standard body length (SL). The objective was to capture sufficient numbers of tunas to characterize the distribution and relative abundance. The TANSYU design was based on the midwater trawl net, Yoko-2, which had been used for sampling sardine, Sardinops melanostictus, by Seikai National Fisheries Research Institute ${ }^{16)}$. The total length of the net was $71.6 \mathrm{~m}$ and the length of the headrope and footrope was $38.6 \mathrm{~m}$. The stretched mesh size was $1,000 \mathrm{~mm}$ at the wings and the first panels of the body, decreasing gradually to $57 \mathrm{~mm}$ in the seventh panels of the body. The dimension of the fishing circle was $144 \times 1,000 \mathrm{~mm}$ mesh around. A codend with a mesh size of $60 \mathrm{~mm}$ was attached to the end of the body. An inner net, 30 and 8 $\mathrm{mm}$ in mesh size, was put inside of the codend to collect samples. The expected mouth opening was approximately $20 \mathrm{~m}$ wide and $18 \mathrm{~m}$ high, at a towing speed of 4.5 $\mathrm{kn}$. The net was designed for a maximum towing speed 
of $5 \mathrm{kn}$. The TANSYU was designed to be used with otter doors $1.7 \mathrm{~m}$ by $2.8 \mathrm{~m}$ in size. A scale model of the TANSYU was constructed and tested in a tank at Nichimo Co., Ltd. to evaluate its design and performance.

Midwater trawling was typically conducted 4 times daily; standard duration of towing was approximately one h. Fifteen strata were set up from the near surface to 300 $\mathrm{m}$, with $20 \mathrm{~m}$ increments for the water depth and separate tows in each stratum were carried out. Depth of the net was determined using the warp length and towing speed which was usually set at 4 to $5 \mathrm{kn}$ against the currents. A net-depth recorder (Furuno FNR-200) was used to monitor continuously the mouth opening and depth of the net throughout the trawling operation.

\section{3) Specimens and data analysis}

As soon as the midwater trawl net was brought on the deck, the collection from the codend was weighed and expressed as whole wet weight. Then, skipjack tuna and other tunas were sorted out from the collection. These specimens were preserved in $80 \%$ ethanol. Skipjack tuna was identified according to the method of Matsumoto et al. ${ }^{7}$. Other tuna species were treated as Thunnus spp. in this study. SL and wet body weight (BW) of these specimens were measured. Shrinkage of juvenile skipjack tuna in $80 \%$ ethanol was about $5 \%$.

Horizontal and vertical distribution of the juveniles was analyzed along with the midwater trawling data and oceanographic data.

Studies on the feeding habit of the juveniles were carried out based on the analysis of the stomach content and related sampling data. The specimens of $581 \mathrm{~K}$. pelamis and 322 Thunnus spp. collected during the 1994 survey were used for the analysis. After measurements of the SL and BW, the stomach of the specimens was cut out from the body. Stomach contents were removed and placed in a glass plate, and identified to the lowest possible taxa using a dissecting microscope. Total wet weight of the stomach contents and weight of each taxon were measured. The stomach content index (SCI) was calculated as an index of food consumption by the following equation,

$$
\mathrm{SCI}=\mathrm{SCW} / \mathrm{BW} \times 100
$$

where SCW is the wet weight of the stomach contents $(\mathrm{g})$ and $\mathrm{BW}$ is the wet body weight ( $\mathrm{g}$ ) of the specimens. We used the index of relative importance (IRI) according to Pinkas et al. ${ }^{12)}$ to evaluate the relationship of the various food materials found in the juvenile stomach. The index was calculated by the following equation,

$$
\mathrm{IRI}=(\mathrm{N}+\mathrm{W}) \times \mathrm{F}
$$

where IRI is the index of relative importance of each food material. $\mathrm{N}$ is the numerical percentage of each food material to the total number of all food materials identified. $\mathrm{W}$ is the weight percentage of each food material to the total weight of all food materials identified. $F$ is the frequency of percentage of occurrence of each food material for the total number of stomachs examined. Stomach fullness and the stage of digestion were observed according to the method of Young and Davis ${ }^{26)}$.

Growth of juvenile skipjack tuna was studied based on the otolith increment analysis. The specimens collected during the 1995 survey were used. Sagittal otoliths of larvae were semi-hemispherical in shape, and measurement of the growth increments was easier than that of the juveniles. The shape of the otoliths of the juveniles became so complicated that it was difficult to observe it, because the growth of the otoliths was accompanied by the extension of the rostrum to postrostrum and increasing thickness. Sagittal otoliths removed from the larval skipjack tuna were cleaned, mounted on a glass plate with enamel resin, and used for the observation of the growth increments ${ }^{25)}$. Sagittal otoliths of the juveniles were removed and cleaned, mounted on a glass plate with enamel resin, and polished on both sagittal planes. We used lapping films, with grit sizes of 9, 3, and $1 \mu \mathrm{m}$. The otolith measurement system (Ratoc System Engineering Inc., Japan) was used for the count of the growth increments and measurement of the increment width. Radii were measured along the line of maximum otolith radius toward the postrostrum. The growth increments were measured at a magnification of $1,000 \times$ for the larvae, $500 \times$ for the juveniles. The specimens for which the increments could not be counted because of the lack of distinctiveness, were rejected. We used the index of completion (C) of the marginal increment according to Tanaka et al.(1981) ${ }^{20)}$ to validate the periodicity of increment formation,

$$
\mathrm{C}=\mathrm{Wn} / \mathrm{Wn}-1 \times 100
$$

where $\mathrm{Wn}$ is the width of the marginal increment $(\mu \mathrm{m})$, and $\mathrm{Wn}-1$ is the width of the previous complete increment $(\mu \mathrm{m})$.

\section{Results and discussion}

\section{1) Collection of juvenile tunas}

Approximately 500 tows of the midwater trawl net were carried out for 5 years. We collected more than 

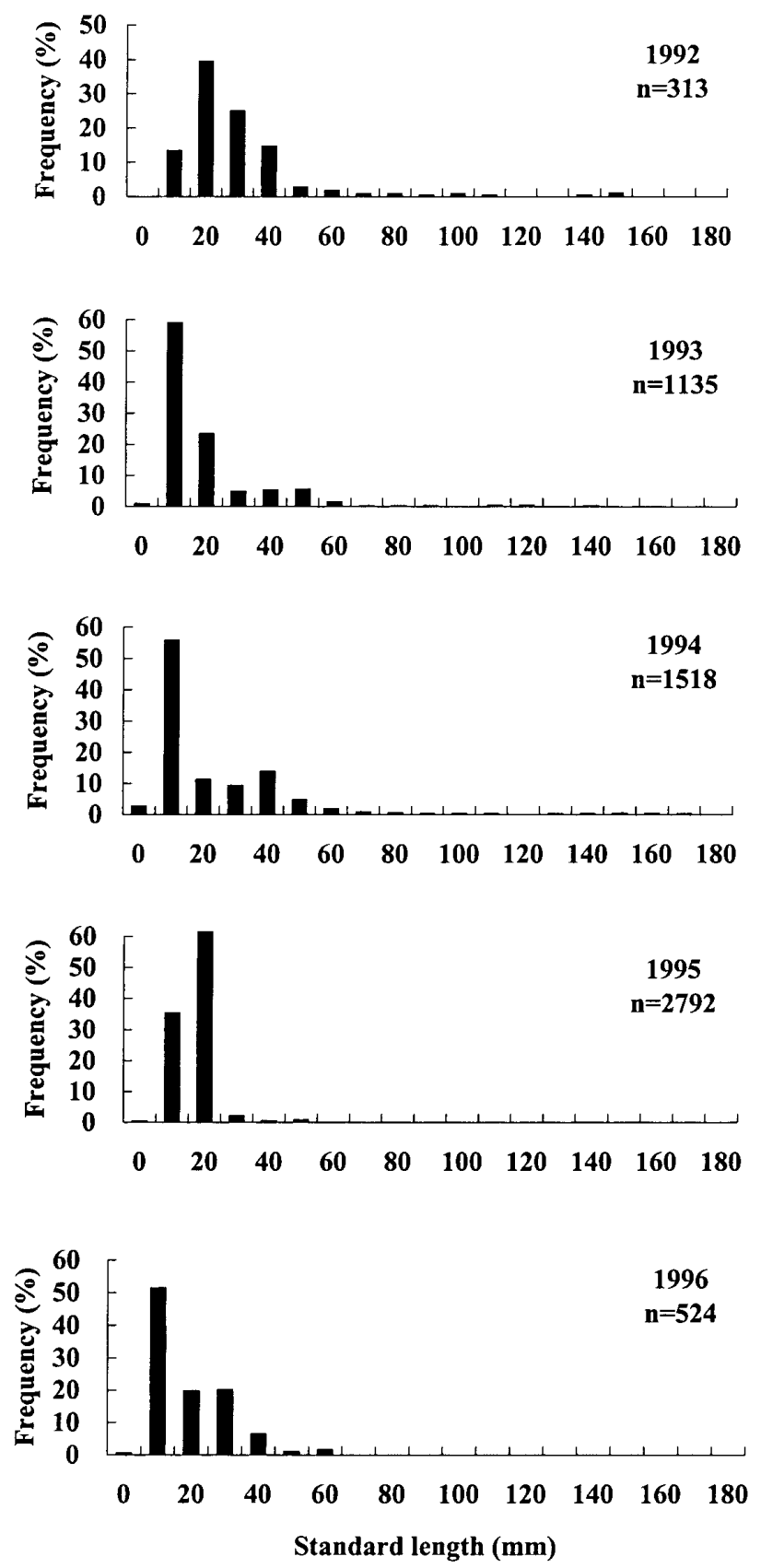

Fig. 2. Length-frequency distribution of Katsuwonus pelamis caught in the tropical western Pacific from 1992 to 1996

8,000 specimens of juvenile tunas, Katsuwonus pelamis and Thunnus spp. The percentage of occurrence of $K$. pelamis in total tows was much higher than that of Thunnus spp. The indices were more than $40 \%$ in all the years. Total catch and the abundance index (total catch / total tows) of $K$. pelamis were also higher than those of Thunnus spp. except for the first survey. The catch of $K$. pelamis showed remarkable annual changes. The maximum value of the abundance index was observed in 1995, being 13 times higher than that in 1992 . The
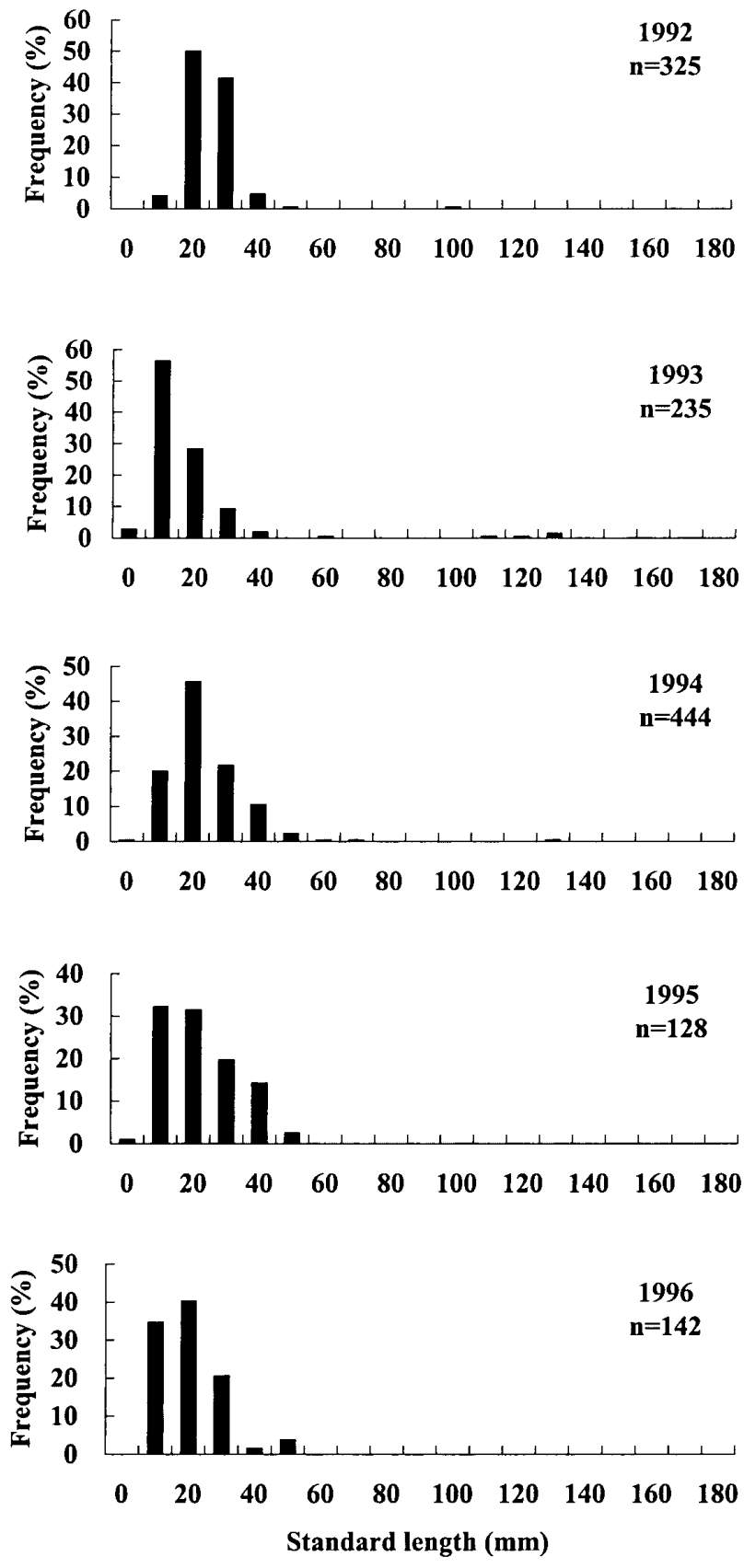

Fig. 3. Length-frequency distribution of Thunnus spp. caught in the tropical western Pacific from 1992 to 1996

changes were attributed to natural factors, namely the annual changes in the abundance of juveniles, as well to artificial factors, namely the difference in the sampling locations, depth, and time of day. Some problems were associated with the quantification of the annual changes in the abundance index.

The size classes of $K$. pelamis and Thunnus spp. were widely represented (Figs. 2 and 3). The SL of $K$. pelamis ranged from 5.5 to $171.6 \mathrm{~mm}$, and that of Thunnus spp. from 8.0 to $148.8 \mathrm{~mm}$. The specimens were at 

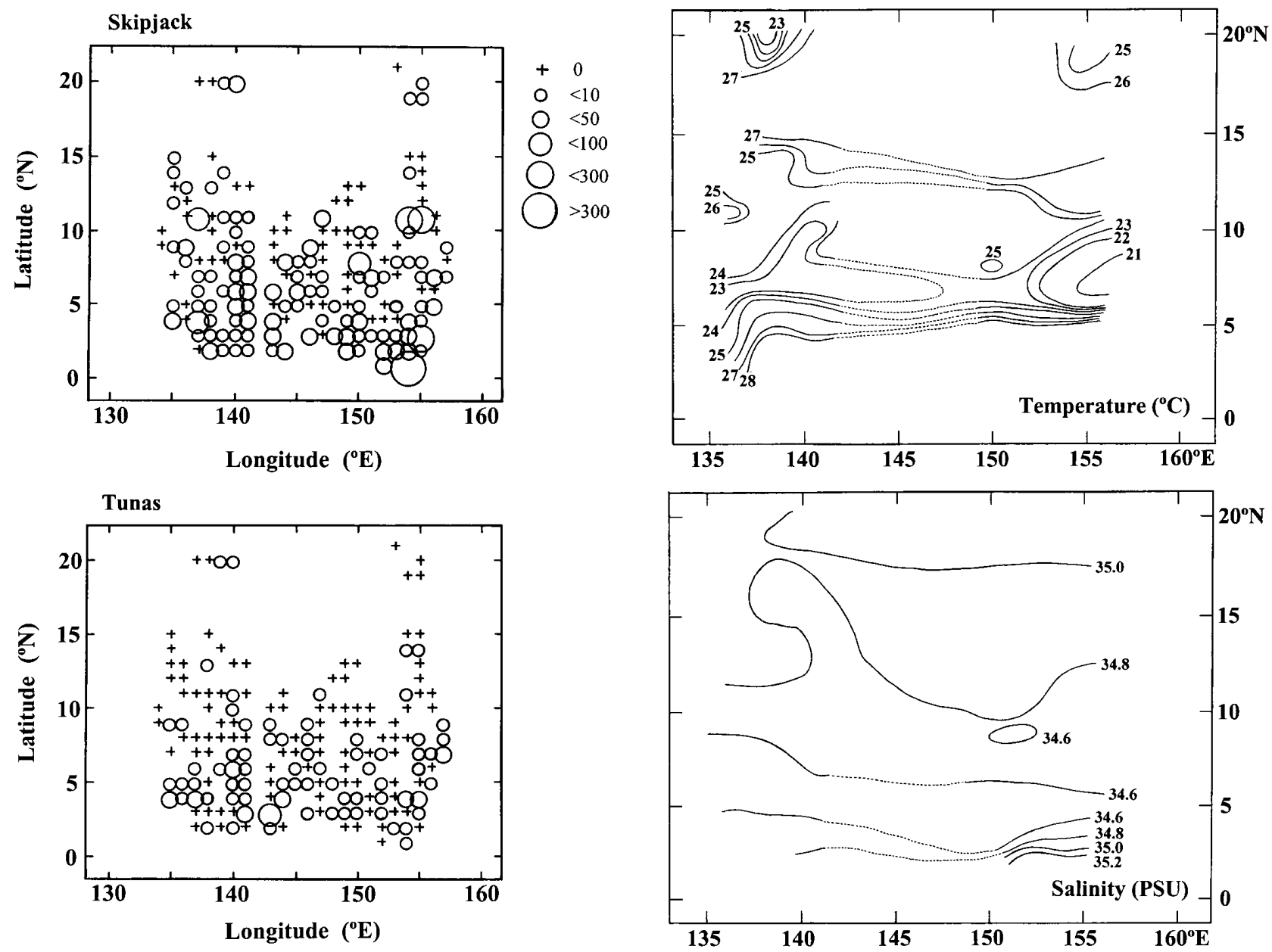

Fig. 4. Horizontal distribution of Katsuwonus pelamis (top) and Thunnus spp. (bottom)

Circles indicate the abundance of juveniles calculated from the total catch of juveniles per total number of tows during 1992-1996, all the years combined. Plus $(+)$ marks indicate negative catch.

the postlarval to early young stages of life of tuna. More than $95 \%$ of them were at the juvenile stage. The size classes of 10-30 $\mathrm{mm}$ SL were always dominant in all the years.

\section{2) Distribution analysis}

Juvenile tunas were widely distributed in the survey area (Fig. 4). K. pelamis occurred over a wider area than Thunnus spp. Year-to-year variation was observed in the distribution of juvenile tunas. In 1992 and 1994, juvenile tunas were abundant in the southern part of the survey area. In 1995, high concentrations of juvenile $K$. pelamis appeared at $2^{\circ}$ and $11^{\circ} \mathrm{N}$ along $155^{\circ} \mathrm{E}$. Juvenile Thunnus spp. were usually abundant in the southern area. The survey area was generally divided by oceanographic conditions as follows: north of $11^{\circ} \mathrm{N}$, the North Equatorial Current (NEC) area; between $11^{\circ}$ and $7^{\circ} \mathrm{N}$, the boundary

Fig. 5. Horizontal distribution of temperature (top) and salinity level (bottom) at 100-m depth based on CTD casts in the 1995 survey cruise

area; south of $7^{\circ} \mathrm{N}$, the North Equatorial Counter Current (NECC) area. The NEC and NECC areas were characterized by a high temperature and high salinity level (Figs. 5 and 6). The boundary area showed a lower temperature and lower salinity level than these areas. The boundary area and the NECC area provided better food conditions for juvenile tunas than the NEC area, because the upwelling in the equatorial region supplies abundant nutrition for the primary production. Therefore, we considered that the NECC area was more suitable than the NEC area for tropical tuna species as a nursery ground for the juveniles.

The vertical distribution of the juvenile tunas was represented by the abundance and percentage of occurrence of juveniles at each depth (Fig. 7). There was a clear difference in the indices between $K$. pelamis and Thunnus spp. K. pelamis were abundant at the depths from 40 to $120 \mathrm{~m}$, while Thunnus spp. were abundant from the surface to $80 \mathrm{~m}$. The depth of the tuna distribution showed limited changes each year, but the relation- 

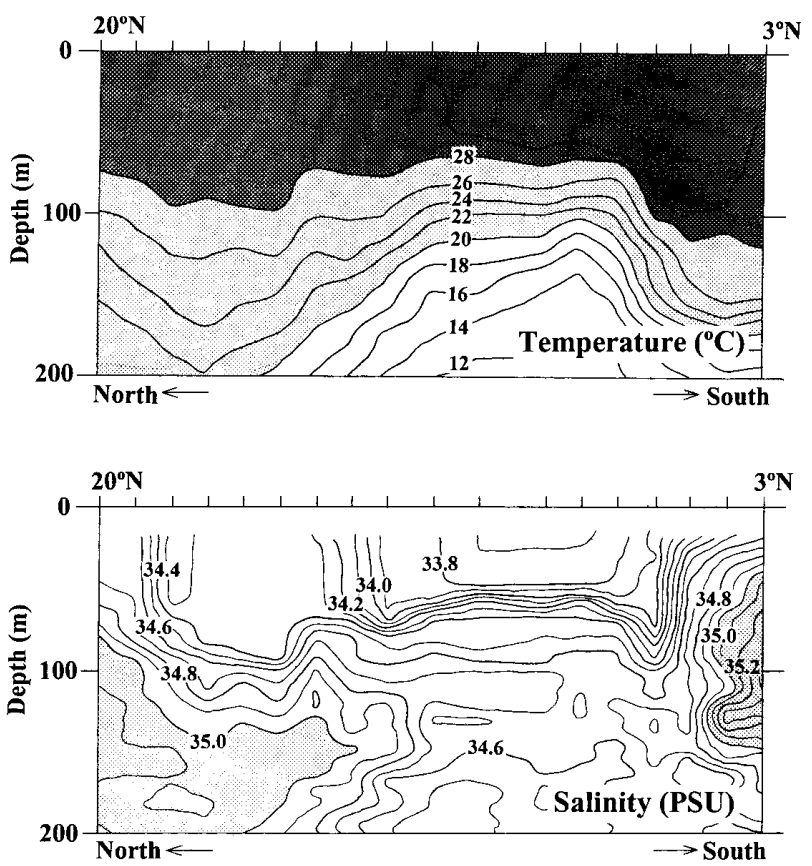

Fig. 6. Vertical distribution of temperature (top) and salinity level (bottom) along $155^{\circ} \mathrm{E}$ cruise track based on CTD casts in the 1995 survey cruise

ship between $K$. pelamis and Thunnus spp. was consistent. These data indicate that the optimal values for the depth for $K$. pelamis distribution are higher than those for Thunnus spp., presumably due to the difference in the optimal temperature. Vertical profiles of temperature from CTD data showed that a mixed layer usually existed between the surface and $80 \mathrm{~m}$ and the thermocline appeared under the mixed layer. Therefore, K. pelamis were mainly distributed from the lower portion of the mixed layer to the upper portion of the thermocline. In contrast, Thunnus spp. were mainly distributed in the mixed layer. Therefore, the optimal temperature for Thunnus spp. was higher than that for $K$. pelamis. The vertical distribution of the juvenile tunas tended to change with the growth stages (Fig. 8). At the early juvenile stage, they appeared at wider depths from the near surface to over $200 \mathrm{~m}$, while larger juvenile tunas were distributed at narrower depths. At the young stage (more than $100 \mathrm{~mm}$ SL), most of them appeared at a depth of about $50 \mathrm{~m}$. The change was attributed to the development of the swimming ability. At the early life stage, many organs related to the locomotion which were incomplete, developed with the growth of the body, and then tunas were able to occur at optimal depths. Our data on the young specimens were fewer than those on the juveniles, and the young specimens were collected only at night. However, this ecological characteristic of tunas should be noted.
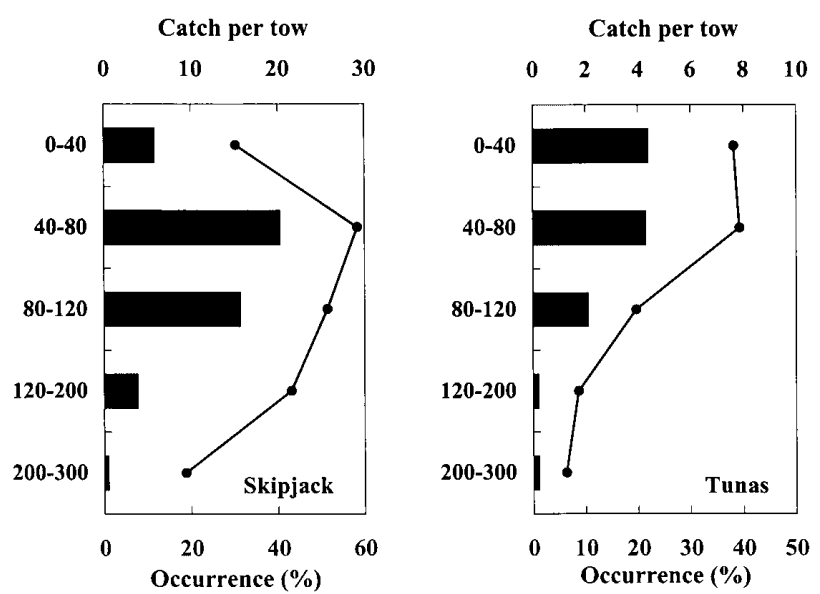

Fig. 7. Vertical distribution of Katsuwonus pelamis (left) and Thunnus spp. (right)

Bars indicate the abundance of juveniles at each depth calculated from the total catch per total number of tows during 1992-1996, all the years combined. Circles with a solid line indicate the percentage of occurrence of juveniles in the total number of tows.

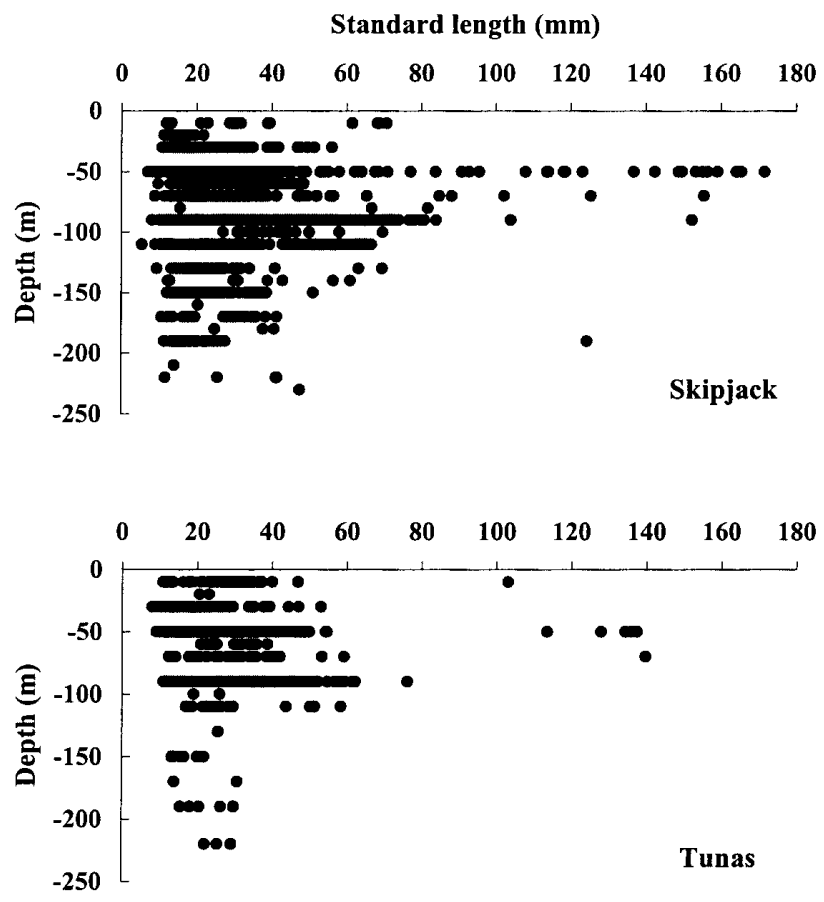

Fig. 8. Relationship between the standard length and depth of sampling for Katsuwonus pelamis (top) and Thunnus spp. (bottom) during 1992-1996, all the years combined

\section{3) Feeding habit}

The SCI fluctuated with the size and individuals (Fig 9). The specimens at the early juvenile stage showed a maximum SCI of more than $15 \%$. In the speci- 

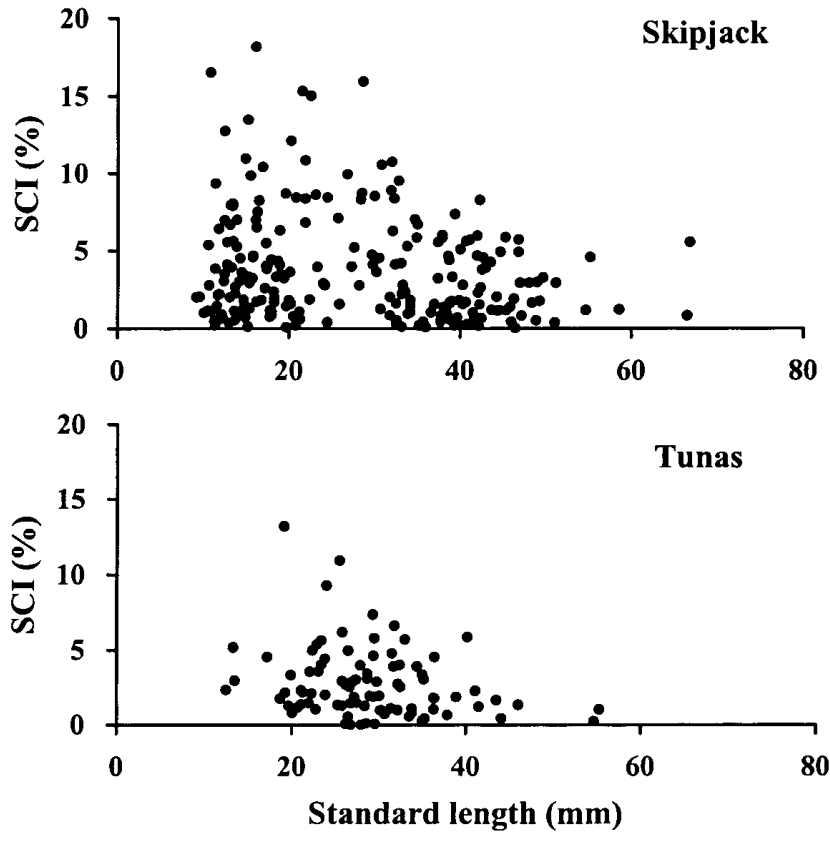

Fig. 9. Relationship between the standard length and the stomach content index (SCI) of Katsuwonus pelamis (top) and Thunnus spp. (bottom)

SCI $(\%)=$ wet weight of the stomach contents / body wet weight $\times 100$. mens larger than $40 \mathrm{~mm}$, the maximum SCI decreased to less than $10 \%$.

The stomach of the juvenile tunas contained fish larvae, Decapoda, Euphausiaceae, Copepoda, Amphipoda, Cephalopoda, and unidentified organisms. Most of the fish larvae could not be identified to the level of taxon because of the digestion. We often found ocean anchovy larvae in the stomachs of the tuna juveniles. Larval $K$. pelamis and Thunnus spp. also appeared in the juvenile stomachs.

The IRI of fish larvae for $K$. pelamis and Thunnus spp. showed the highest values of all food materials in the NEC and NECC areas (Table 1). These results suggest that fish larvae are the major food material for juvenile tunas in the tropical western Pacific. In K. pelamis, there was a difference in the IRI of other food materials among areas. Euphausiaceae were the second most important food material in terms of IRI in the NEC area, while Copepoda in the NECC area. In contrast, the IRI of fish larvae in Thunnus spp. was remarkably high and that of other food materials was fairly low and the values did not change significantly between the two areas. The differences in food selection indicated that Thunnus spp. were stronger piscivorous animals than $K$. pelamis at the juve-

Table 1. Main prey taxa of Katsuwonus pelamis and Thunnus spp. juveniles in the North Equatorial Current (NEC) and the North Equatorial Counter Current (NECC) areas

K. pelamis

\begin{tabular}{|c|c|c|c|c|c|c|c|c|}
\hline & \multicolumn{4}{|c|}{ NEC area } & \multicolumn{4}{|c|}{ NECC area } \\
\hline & $\mathrm{F} \%$ & $\mathrm{~N} \%$ & W\% & IRI & $\mathrm{F} \%$ & $\mathrm{~N} \%$ & W\% & IRI \\
\hline Fish larvae & 78.9 & 84.1 & 94.7 & $14,107.3$ & 77.4 & 62.8 & 77.4 & $10,851.5$ \\
\hline Euphausiacea & 16.7 & 6.5 & 3.2 & 162.0 & 6.2 & 3.1 & 0.9 & 24.8 \\
\hline Copepoda & 1.1 & 0.3 & 0.0 & 0.3 & 8.9 & 15.9 & 1.9 & 158.4 \\
\hline Amphipoda & 4.4 & 1.3 & 0.8 & 9.2 & 1.4 & 1.4 & 0.1 & 2.1 \\
\hline Cephalopoda & 0.0 & 0.0 & 0.0 & 0.0 & 4.1 & 2.4 & 13.9 & 66.8 \\
\hline Others & 0.0 & 0.0 & 0.0 & 0.0 & 3.4 & 2.8 & 0.6 & 11.6 \\
\hline Unidentified & 23.3 & 7.8 & 1.4 & 214.4 & 20.5 & 11.7 & 5.2 & 346.5 \\
\hline \multicolumn{9}{|l|}{ Thunnus spp. } \\
\hline & \multicolumn{4}{|c|}{ NEC area } & \multicolumn{4}{|c|}{ NECC area } \\
\hline & $\mathrm{F} \%$ & N\% & W\% & IRI & $\mathrm{F} \%$ & $\mathrm{~N} \%$ & W\% & IRI \\
\hline Fish larvae & 75.0 & 90.5 & 92.6 & $13,732.5$ & 84.7 & 92.8 & 97.7 & $16,135.4$ \\
\hline Euphausiacea & 3.9 & 1.5 & 1.7 & 12.5 & 0.0 & 0.0 & 0.0 & 0.0 \\
\hline Copepoda & 0.0 & 0.0 & 0.0 & 0.0 & 0.0 & 0.0 & 0.0 & 0.0 \\
\hline Amphipoda & 0.0 & 0.0 & 0.0 & 0.0 & 0.0 & 0.0 & 0.0 & 0.0 \\
\hline Cephalopoda & 1.3 & 0.5 & 1.3 & 2.3 & 1.2 & 1.2 & 0.6 & 2.2 \\
\hline Others & 0.0 & 0.0 & 0.0 & 0.0 & 0.0 & 0.0 & 0.0 & 0.0 \\
\hline Unidentified & 18.4 & 7.5 & 4.4 & 219.0 & 11.8 & 6.0 & 1.7 & 90.9 \\
\hline
\end{tabular}

F: \% frequency of occurrence, $\mathrm{N}: \%$ in number, $\mathrm{W}: \%$ in weight,

IRI: Index of relative importance of each prey item. 

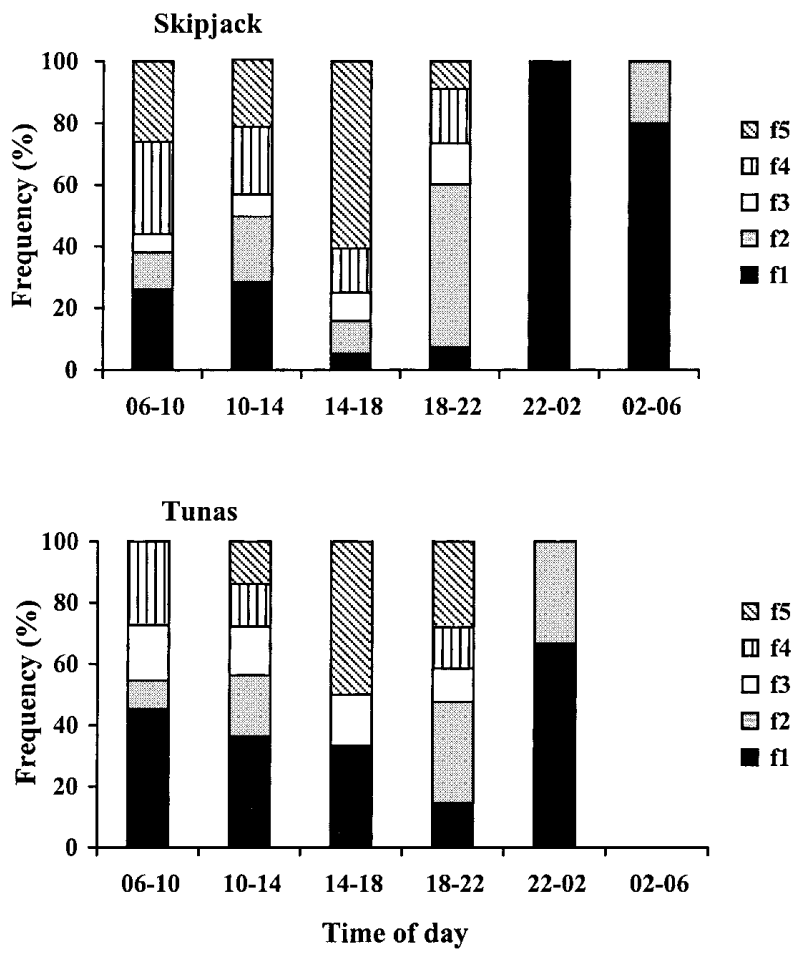

Fig. 10. Diel change in the stomach fullness of Katsuwonus pelamis (top) and Thunnus spp. (bottom) F score indicates the fullness of the stomach contents: f1, empty; f2, less than half-full; f3, half-full; f4, more than half-full; f5, full.

nile stage.

The changes in stomach fullness with the time of the day indicated a clear diurnal pattern of feeding activity (Fig. 10). In the daylight (from 6:00 a.m. to 6:00 p.m.), the proportion of stomach fullness based on scores from 3 to 5 (stomach filled with food by more than half) was dominant in all the specimens examined. In the night (from 6:00 p.m. to 6:00 a.m.), the proportion of empty stomachs or stomachs filled with a small amount of prey tended to increase. These results indicated that juvenile

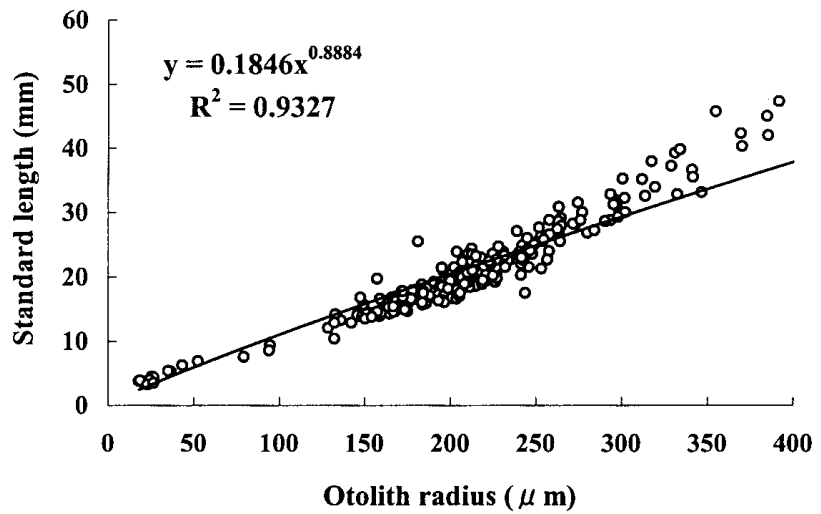

Fig. 11. Relationship between standard length and otolith radius in Katsuwonus pelamis tunas fed only in the daylight. The stage of digestion also changed with the diurnal periodicity. The prey in the juvenile stomachs was more digested in night samples than in day samples. The daily feeding habits of juvenile tunas in this study corresponded to those of the larvae and adults reported in the previous studies $3,9,10,14,22-24,26$. Therefore, the feeding habits of the tunas were consistent from larvae to adults.

\section{4) Growth of juvenile skipjack}

A close linear relationship was found between SL and the maximum otolith radius in skipjack larvae and juveniles (Fig. 11). The first increment was observed in the first ring outside of the core and primordium based on the report of Radtke ${ }^{13)}$. The increment width tended to increase gradually from the core to the edge of the otoliths. The width from the first to the fifth increments was narrow, ranging from 2 to $4 \mu \mathrm{m}$. The width of the increment out of the tenth one increased to around $20 \mu \mathrm{m}$

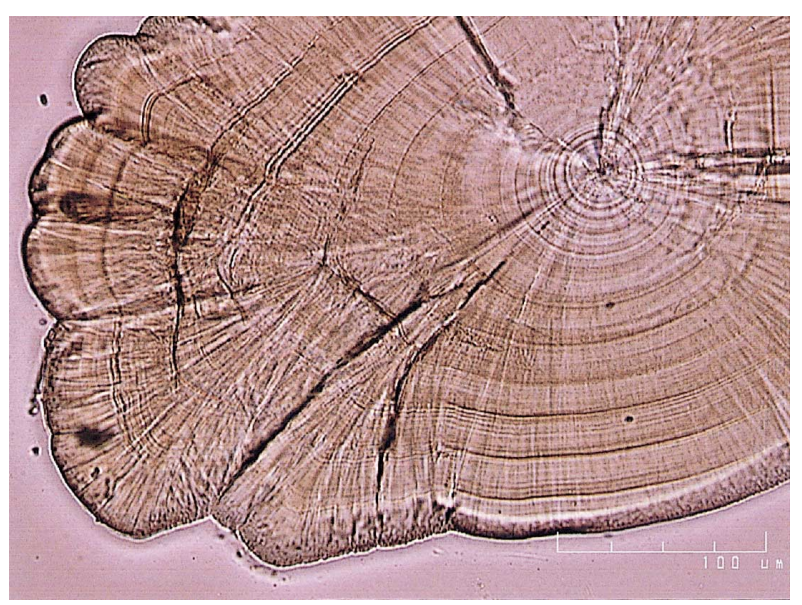

Fig. 12. Light micrograph of sagittal otolith of a juvenile Katsuwonus pelamis $(\mathrm{SL}=\mathbf{2 9 . 8} \mathrm{mm})$

Fifteen daily increments were counted using the otolith measurement system.

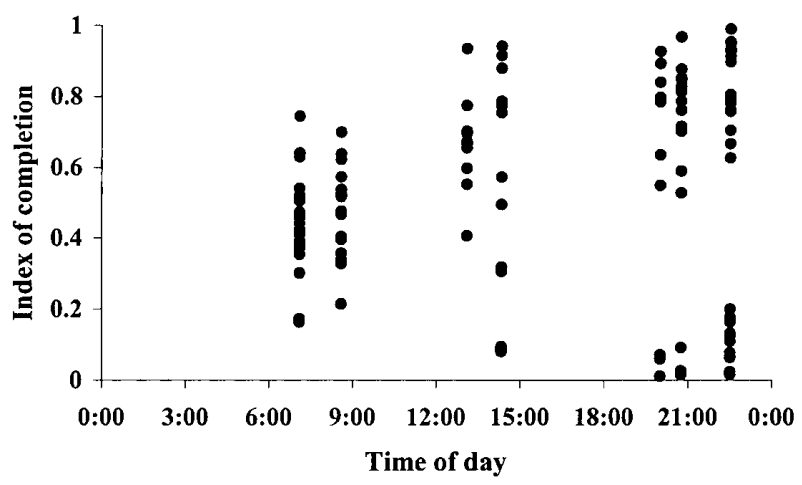

Fig. 13. Diel change in the index of completion of the marginal increment of sagittal otolith 


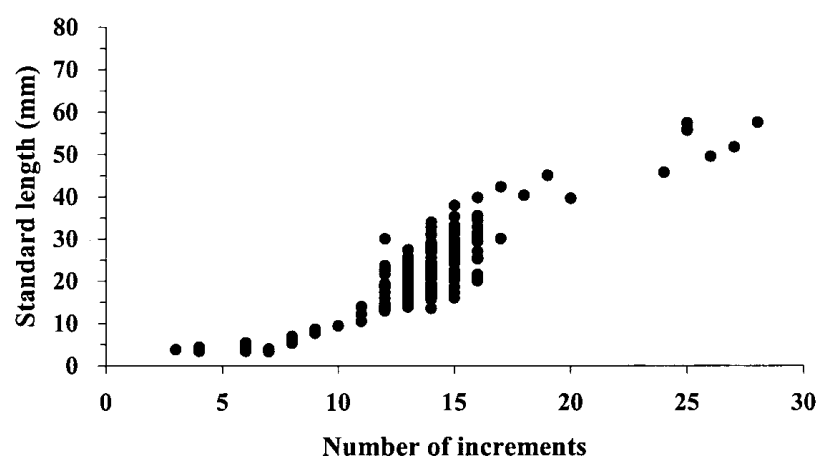

Fig. 14. Relationship between the number of increments of the sagittal otolith and the standard length

(Fig. 12).

The indices $\mathrm{C}$ of juvenile specimens changed with the time of the day (Fig. 13). The values of the indices of the specimens collected from 3:00 to 6:00 a.m. were approximately $30-60 \%$. In the afternoon, from 1:00 to 3:00 p.m., the indices increased to $50-90 \%$, and then reached a value of $100 \%$ after 6:00 p.m., implying that the marginal increment had been completed. Therefore, the increment formation indicated a daily periodicity. Subdaily increments were found between daily increments. Out of the tenth increment, there were about 5-8 subdaily increments (Fig. 12).

The relationship between the number of daily increments and the SL of the larval and juvenile skipjack is shown in Fig. 14. The changes in the growth rate were observed at the ages corresponding to the 12th increment. Before the 12th increment, namely the first period of the life history, the SL of skipjack increased slowly. After the 12th increment, growth was more rapid than in the first period. The variation of the SL for the same number of daily increments was considered to reflect the change in the growth speed among individuals. The metamorphosis corresponding to the transformation from larval to juvenile periods in the skipjack was observed for a total length of approximately $12 \mathrm{~mm}$. Our data indicated that the growth rate of the skipjack increased after the metamorphosis, which was associated with the development of the locomotive and digestive organs.

\section{Summary and conclusion}

The midwater trawl net TANSYU enabled to collect large numbers of juvenile tunas during both day and night, which would not have been possible with the sampling gears previously available. The results of our survey demonstrated that TANSYU was effective for collecting juveniles of skipjack tuna and other tunas. In the previous studies, various sampling gears were used for sampling tuna larvae, the results of which demonstrate that the maximum size of the tunas that were collected with smaller plankton nets was about $12 \mathrm{~mm}$ (the usual size being $3-5 \mathrm{~mm}^{1,2,11,15)}$ ). Thus, tunas larger than $10 \mathrm{~mm}$ can easily escape from these gears. Davis et al. ${ }^{2)}$ pointed out that net avoidance by larvae should be considered in calculating the estimates of abundance of tuna larvae.

The results of collections of juveniles (larger than 10 $\mathrm{mm}$ ) which had been reported in a few studies ${ }^{5,6,17)}$ suggested that juvenile tunas avoided the small trawl nets. The mouth opening and the towing speed of the TANSYU were much higher than those of the small trawl nets used in the previous studies. We therefore expected that the size of the specimens would be larger than that of the specimens collected in the previous studies if the survey area and period were appropriately selected. Indeed, the size range of skipjack tuna and other tunas collected with the TANSYU was much wider than that of the tunas collected with smaller nets. In addition, large numbers of juvenile tunas were collected.

Skipjack and other tunas that reach the young stage are able to swim much faster than juveniles. In this study, the number of young tunas collected was low, and these fish were caught only at night. The results indicate that net avoidance by young fish affected the number of captured specimens. The results of our study, based on previous studies on the sampling of skipjack and other tunas, show that juveniles with a wider size range can be collected by using a trawl net with a larger mouth opening and a high towing speed, as in the case of the TANSYU. A small ring net is appropriate for research based on the sampling of larvae because of the simplicity of operation. However, if it is necessary that diurnal patterns of vertical distribution of juvenile skipjack and other tunas be investigated, the appropriate time and depth of towing should be selected, because ecological characteristics drastically affect the amount of collected specimens. Sampling of young skipjack and other tunas, on the other hand, should be conducted at night with a trawl net having a large mouth opening, or with a new net that would minimize net avoidance by fish at the young stage.

Our studies on the early life history of the skipjack provided important information. We observed that the distribution and feeding habit of the juveniles of $K$. pelamis and Thunnus spp. were evidently different, although they were similarly classified into highly migratory species. Juvenile $K$. pelamis were widely distributed in the area from the North Equatorial Current to the North Equatorial Counter Current. Juvenile Thunnus spp. were abundant in the area of the North Equatorial Counter Current. The abundance of skipjack and yellowfin tuna lar- 
vae in the tropical western Pacific from October to December was larger than that in other areas of the Pacific $^{11)}$. These results indicate that the offshore areas of Palau and Micronesia are important for larval and juvenile tunas as a nursery ground at the early life stages ${ }^{18)}$. We consider that adult skipjack and yellowfin tuna spawn in the vast area of the tropical western Pacific, and that they are distributed and grow in the same area at least until the juvenile stage. Although in our study, the amount of tunas collected at the young stage was insufficient, analysis of the stomach contents of adult tunas indicated that young tunas were distributed in the tropical western Pacific all the year round ${ }^{8}$. Therefore, the area is also important for tunas at the young stage as a nursery ground.

We observed that the vertical distribution of the juveniles was obviously different between $K$. pelamis and Thunnus spp. According to Ueyanagi ${ }^{21)}$, the abundance of larval $K$. pelamis increased vertically from the near surface zone to the 40-50 $\mathrm{m}$ depth in the daytime. In contrast, three Thunnus species, T. albacares, T. obesus, and T. alalunga, were abundant at shallower depths than in the case of $K$. pelamis. Boehlert and Mundy ${ }^{1)}$ also reported that the vertical distribution of larvae of $K$. pelamis was deeper than that of Thunnus spp. in the Hawaiian waters. Therefore, these results indicated that the optimal temperature for juveniles is different, that is, K. pelamis preferred lower temperatures compared to Thunnus spp. In addition, the difference in the distribution habits between $K$. pelamis and Thunnus spp. was consistent from the larval to juvenile stages.

Another important aspect of the early life study is the need to conduct a quantitative examination of the distribution in relation to sampling gears. This information is essential for the validation of the recruitment process of tuna species. In order to estimate the abundance of juveniles, examination of the avoidance of and escape from sampling gears as well as clarification of the discrepancy in the research data is necessary. In our study, however, the differences in the relative abundance of juveniles between $K$. pelamis and Thunnus spp. could be estimated. The results of juvenile collections indicated that the relative abundance of $K$. pelamis was higher than that of Thunnus spp. in the tropical western Pacific at least from October to December.

The present survey area, located in the northern part of the equator, is characterized by a relatively high temperature all the year round, suggesting that the tropical area displays lower seasonal fluctuations and a higher stability than the temperate area. These oceanographic conditions allow the tropical tuna species to reproduce independently of seasons. In addition, the stability of the physical and biological conditions in the tropical area is favorable for the survival and growth at the vulnerable early life stage.

\section{References}

1) Boehlert, G. W. \& Mundy, B. C. (1994): Vertical and onshore-offshore distributional patterns of tuna larvae in relation to physical habitat features. Mar. Ecol. Prog. Ser., 107, 1-13.

2) Davis, T. L. O., Jenkins, G. P. \& Young, J. W. (1990): Diel patterns of vertical distribution in larvae of southern bluefin Thunnus maccoyii, and other tuna in the East Indian Ocean. Mar. Ecol. Prog. Ser., 59, 63-74.

3) Dragovich, A. (1971): Food of skipjack tuna in the Caribbean Sea and adjacent waters. FAO Fish. Rep., 72(2), 2740.

4) Food and Agriculture Organization (1999): Catches and Landings. FAO Yearbook, Fishery Statistics, 84, 321323.

5) Higgins, B. E. (1970): Juvenile tunas collected by midwater trawling in Hawaiian waters, July-September 1967. Trans. Am. Fish. Soc., 99(1), 60-69.

6) King, J. E. \& Iversen, R. T. B. (1962): Midwater trawling for forage organisms in the central Pacific, 1951-1956. Fish. Bull., 62, 271-321.

7) Matsumoto, W. M., Skillman, R. A. \& Dizon, A. E. (1984): Synopsis of biological data on skipjack tuna, Katsuwonus pelamis. NOAA Tech. Rep. NMFS Circ., 451, pp. 92.

8) Mori, K. (1972): Geographical distribution and relative apparent abundance of some scombrid fishes based on the occurrences in the stomachs of apex predators caught on tuna longline. 1. Juvenile and young of skipjack tuna (Katsuwonus pelamis). Bull. Far Seas Fish. Res. Lab., 6, 111-157 [In Japanese with English summary].

9) Nakamura, E. L. (1965): Food and feeding habits of skipjack tuna (Katsuwonus pelamis) in the Marquesas and Tuamotu islands. Trans. Am. Fish. Soc., 94(3), 236-242.

10) Nishikawa, Y. (1975): Feeding of larval and juvenile skipjack tuna in relation to the development of their stomachs. Bull. Far Seas Fish. Res. Lab., 12, 221-236.

11) Nishikawa, Y. et al. (1985): Average distribution of larvae of oceanic species of scombrid fishes, 1956-1981. Far Seas Fish. Res. Lab. S Ser., 12, pp.99 [In Japanese].

12) Pinkas, L., Oliphant, M. S. \& Iverson, I. L. K. (1971): Food habits of albacore, bluefin tuna, and bonito in California waters. Fish Bull., 152, 1-139.

13) Radtke, R. L. (1983): Otolith formation and increment deposition in laboratory-reared skipjack tuna, Katsuwonus pelamis, larvae. NOAA Tech. Rep. NMFS, 8, 99-103.

14) Strasburg, D.W. (1959): An instance of natural mass mortality of larval frigate tuna in the Hawaiian waters. $J . d u$ Cons. Int. Explor. Mer. 24(2), 255-263.

15) Strasburg, D. W. (1960): Estimates of larval tuna abundance in the central Pacific. Fish. Bull., 60, 231-255.

16) Takeshita, K. et al. (1988): Acoustic survey of spawning sardine, Sardinopus melanosticta in the coastal waters of west Japan. Bull. Seikai Reg. Fish. Res. Lab., 66, 101117 [In Japanese with English summary]. 
17) Takuno, H. \& Ueyanagi, S. (1978): Results of midwater trawl investigations for larval fishes in the tropical western Pacific. Far Seas Fish. Res. Lab., pp.55 [In Japanese].

18) Tanabe, T. et al. (1998): Distribution of juvenile skipjack Katsuwonus pelamis and tuna Thunnus spp. based on a midwater trawl net survey off Palau and Micronesia. Bull. Tohoku Natl. Fish. Res. Inst., 60, 15-22 [In Japanese with English summary].

19) Tanabe, T. \& Niu, K. (1998): Sampling juvenile skipjack tuna, Katsuwonus pelamis, and other tunas, Thunnus spp., using midwater trawls in the tropical western Pacific. Fish. Bull., 96, 641-646.

20) Tanaka, K., Mugiya, Y. \& Yamada, J. (1981): Effects of photoperiod and feeding on daily growth patterns in otoliths of juvenile Tilapia nilotica. Fish. Bull., 79, 459465.

21) Ueyanagi, S. (1969): Observations on the distribution of tuna larvae in the Indo-Pacific Ocean with emphasis on the delineation of the spawning areas of the albacore, Thunnus alalunga. Bull. Far Seas Fish. Res. Lab., 2,
177-254 [In Japanese with English summary].

22) Ueyanagi, S. et al. (1973): Report on experiments on the development of tuna culturing techniques. Far Seas Fish. Res. Lab. S Ser., 8, pp.165 [In Japanese with English summary].

23) Uotani, I. et al. (1990): Feeding habit of bluefin tuna Thunnus thynnus larvae in the western north Pacific Ocean. Nippon Suisan Gakkaishi, 56(5), 713-717 [In Japanese with English summary].

24) Waldron, K. D. \& King, J.E. (1963): Food of skipjack in the central Pacific. FAO Fish. Rep., 6(3), 1431-1457.

25) Watanabe, Y. \& Kuroki, T. (1997): Asymptotic growth trajectories of larval sardine (Sardinops melanostictus) in the coastal waters off western Japan. Mar. Biol., 127, 369-378.

26) Young, J. W. \& Davis, T. L. O. (1990): Feeding ecology of larvae of southern bluefin, albacore and skipjack tunas (Pisces: Scombridae) in the eastern Indian Ocean. Mar. Ecol. Prog. Ser., 61, 17-29. 